\title{
The Frequency of Port-Site Infection in Laparoscopic Cholecystectomies
}

\author{
Md. Rezaul Alam¹, Muhammad Nuruzzaman², Mahbuba Begum³, Md. Abdul Alim4, \\ Md. Mostafizur Rahman ${ }^{5}$, Md. Rabiul Karim ${ }^{6}$, Md Insanul Alam
}

\section{Abstract}

Introduction: Laparoscopic surgery was a revolution in the field of surgery. Despite many benefits, the technique is associated with certain complications including PSI. PSI, although less common is annoying both for the surgeon and the patient, and cripple the benefits of MSI. PSI not only increases the economic burden, pain and Hospital stay of patient but also harm the reputation of the attending Surgeon and hospital. Materials and Methods: This observational study carried out by the Department of general surgery at Medical College for Women \& Hospital (MCWH), Uttara, Dhaka over a period of one year (July 2017 to June 2018). The study was carried out in 108 patients who underwent LC. AIM was to study the frequency of port site infection. Results: In the current study, 108 patients including 92 females and 16 males were operated. A total of 12 patients had PSI. Infection was seen in one male patients and 11 female patients. Age range was 20-75 years. Port -site involved was epigastric, which developed infection in 7 patients, followed by umbilical port which got infected in 5 patients. Gall bladder was extracted through epigastric port site in 29 patients and through umbilical port site in 79 patients. 7 cases are superficial infection with foreign body reaction, 2 cases are deep infection and 3 cases are mycobacterial tuberculous infection. Conclusion: LC is associated with a low risk of port site infection which in most cases is only superficial and responds to local measures. Infection is most commonly seen at port site through which gall bladder was extracted.

Keywords: Laparoscopic cholecystectomy (LC), Port-site infection (PSI), Minimal invasive surgery (MSI).

Number of Tables: 02; Number of Figures: 02; Number of References: 25; Number of Correspondence: 05.

*1. Corresponding Author:

Dr. Md. Rezaul Alam, MBBS, FCPS(Surgery) Assistant Professor (cc), Department of Surgery Medical College for Women \& Hospital, Uttara, Dhaka. Email: rezaul4151972@gmail.com Mobile:01715348661

2. Dr. Muhammad Nuruzzaman, MBBS, FCPS (Surgery) Assistant Professor, Department of Surgery Medical College for Women \& Hospital, Uttara, Dhaka.

3. Dr. Mahbuba Begum, MBBS, FCPS (Surgery) Associate Professor \& Head Department of Surgery Medical College for Women \& Hospital, Uttara, Dhaka.

4. Dr. Md. Abdul Alim, MBBS, FCPS(Surgery) Asst. Professor \& Head, Department of Surgery North Bengal Medical College \& Hospital, Sirajgonj.

5. Dr. Md. Mostafizur Rahman, MBBS, MS (Urology) Assistant Professor (cc), Department of Urology Medical College for Women \& Hospital, Uttara, Dhaka.

6. Dr. Md. Rabiul Karim, MBBS, FCPS Assistant Professor, Department of Surgery Monno Medical College, Manikgonj.

7. Dr. Md Insanul Alam

Assistant Professor(cc), Department of Orthopaedic Medical College for Women \& Hospital, Uttara, Dhaka-1230.

\section{Introduction:}

Laparoscopic surgery also known as minimal invasive surgery (MIS) is a technique, in which operations can be performed using small incisions away from the site of pathology. It revolutionized the surgical world when first introduced in the beginning of nineteenth century. Cholecystectomy is the most common operation of the biliary tract and the second most common operative procedure performed nowadays ${ }^{1}$.

Laparoscopic cholecystectomy is now considered the gold standard procedure for management of cholelithiasis ${ }^{2}$. Despite many benefits such as decrease post operative pain, early mobility, early return to work and small scars, ${ }^{3}$ the technique carries certain complications including PSI.

PSI not only increases the pain and hospital stay of the patient but also increases work load on hospital staff, thus decreasing the cost effectiveness of a minimally invasive procedure.

The Centers for Disease Control and Prevention classification (CDC) categorized surgical site infection into incision-site infection and organ-space infection. The incision-site infection is further subdivided into "superficial" in which only skin and subcutaneous tissue is infected and "deep" where fascia and muscles are infected".

In our study of PSI in LC, only the incisional category is applicable and has been used.

In this study we analyzed our experience of port site infection in LC.

Gallstone disease is the most common pathology of the biliary tract. It is a major health problem not only in Bangladesh but also worldwide 
in the adult population. Open cholecystectomy remained the procedure of choice for about 100 years till 1987 when Philip Mouret performed first LC in France 5 .

The main objective of $\mathrm{LC}$ is to minimize the traumatic insult to the patients without compromising the safety and efficacy of treatment compared with traditional open cholecystectomy ${ }^{6}$. At some centers LC is performed as day case surgery. All patients with symptomatic gall stones disease and even acute cholecystitis are the candidates for the LC. Obesity, old age, previous abdominal surgical intervention and liver cirrhosis are no longer contraindications ${ }^{7}$. Early LC for acute cholecystitis is still performed by only a minority of surgeons because early laparoscopic cholecystectomy for the management of acute cholecystitis is considered to be associated with more complications ${ }^{8}$. Previous attacks of cholecystitis are associated with adhesion formations thus making cholecystectomy more difficult and most common cause of conversion rate from LC to open cholecystectomy ${ }^{9}$. The overall frequency of major complications is less than $5 \%$ in laparoscopic cholecystectomy.

PSI due to non-tuberculosis mycobacterium has been a concern for the laparoscopic surgeons of late as it leads to a protracted morbid state. It washes away all the advantages of the laparoscopic surgery and irritates the surgeon as well as the patient equally due to persistent redundant infection.

\section{Material and Methods:}

This prospective study was conducted in the department of General Surgery at Medical College for Women and Teaching Hospital, Uttara, Dhaka over a period of one year (July 2017 to June 2018). Approval from the hospital ethical committee was obtained. All the patients with symptomatic gallstones were admitted through outdoor department, their age range was between (20-75 years).

Patients with age $<20$ years, acute pancreatitis, choledocholithiasis, skin infections, pregnancy, past history of peritonitis and bleeding disorders were excluded from the study. Procedure was discussed in detail with the patient and written informed consent was obtained.

All the patients were admitted to surgical ward a day before surgery and were given 3 doses of third generation antibiotics (ceftriaxone 1gm). First dose at the time of induction of anesthesia and rest after the surgery. The patients were monitored for port site infection using standard National Nosocomial Infections Surveillance (NNIS) System definitions given by the Centers for Disease Control and Prevention (CDC).

\section{Operative technique:}

All the patients were operated under General anesthesia. After painting with Povidone-iodine solution (from the nipple line to the inguinal ligaments and laterally to the anterior superior iliac spine) and draping, a $1.5-\mathrm{cm}$ longitudinal incision was made at the inferior aspect of the umbilicus, and then deepened through the subcutaneous fat to the anterior rectus sheath. A Kocher clamp was used to grasp the reflection of the linea alba onto the umbilicus and elevate it. A $1 \mathrm{~cm}$ longitudinal incision was made in the linea alba with a No. 15 blade. The peritoneum was elevated between two straight clamps and incised so as to afford safe entry into the abdominal cavity. A 10 -mm blunt trocar was placed into the abdominal cavity, and pneumoperitoneum created. Or sometimes introduced verress needle and pneumoperitonium created. Another way $10 \mathrm{~mm}$ trocher and cannula introduced blindly and pneumoperitonium created.

The laparoscope was white-balanced and advanced into the abdominal cavity. A $1.2-\mathrm{cm}$ incision is made three fingerbreadths below the xiphoid process and deepened into the subcutaneous fat. A $10-\mathrm{mm}$ trocar was advanced into the abdominal cavity under direct vision in the direction of the gallbladder through the abdominal wall, with care to enter just to the right of the falciform ligament. The table was then adjusted to place the patient in a reverse Trendelenburg position with the right side up to allow the small bowel and colon to fall away from the operative field. The optimal position for lateral 5-mm ports were chosen by the surgeon and the lateral skin incisions were made, and two 5-mm trocars were advanced into the peritoneal cavity under direct vision. Calot's triangle was identified and all the areolar tissue was removed identifying cystic duct and artery clearly. Both the structures were clipped and cut separately. Cholecystectomy was completed using L-hook and hemostasis rechecked and secured. Gall bladder was extracted from epigastric or umbilical port site depending upon surgeon's choice. The umbilical port was repaired under direct vision by OS $61 / 0$ vicryl. Then removal of gas and trocar respectively. All the skin incision was closed using OS 6 1/0 vicryl.

Occasionally drain was used which was removed $1 \mathrm{st} / 2 \mathrm{nd}$ postoperative day. Patients were discharged on $1 \mathrm{st} / 2 \mathrm{nd}$ postoperative day. Port sites were evaluated clinically for infection on day 5 after surgery and wound infections were dealt with local washes with Normal Saline and surgical dressings plus empirical antibiotics. Stitches were removed after 7 days of surgery. All patients were followed for a period of one month.

Evaluation was done for postoperative fever, erythema, discharge from the wound. Local cultures were taken from the wound margin, discharge or aspirate of haematoma. Postoperative infection was considered to be present if cultures were positive.

\section{Results:}

In our study LC was performed in 108 patients, which included 92 females (85\%) and 16 males $(15 \%)$. Their age range was between 20 - 75years (Table I).

Table-I: Age range of the patients.

\begin{tabular}{lll}
\hline Age zone & $\mathbf{N}$ & $\%$ of age \\
\hline $20-30$ years & 30 & $28 \%$ \\
\hline $30-40$ years & 36 & $33 \%$ \\
\hline $40-50$ years & 20 & $19 \%$ \\
\hline $50-60$ years & 14 & $14 \%$ \\
\hline $60-70$ years & 07 & $06 \%$ \\
\hline$>70$ years & 01 & $01 \%$ \\
\hline
\end{tabular}


Out of these 108 patients $12(11 \%)$ of patients developed PSI. The patients who developed wound infections includes 11 females and one males (Table-II). Most common port site involved was epigarstric port, which developed infection in 7 patients $(58 \%)$, followed by umbilical port which got infected in 5 patient (42\%). Gall bladder was extracted through epigastric port site in 29 patients $(27 \%)$ and through umblical port site in 79 patients $(73 \%)$.

Out of the 12 patients who developed PSI, gallbladder was perforated while extraction with spillage of bile and stones in 3 cases $(25 \%)$. Out of these 12 patients who developed wound infection, $2(17 \%)$ patients had operative findings of acute cholecystitis (empyema gall bladder) and 3 patients (25\%) develop port site tuberculosis. All others 4 (33\%) was having chronic cholecystitis with foreign body granuloma.

\section{Table-II: Frequency of wound infection.}

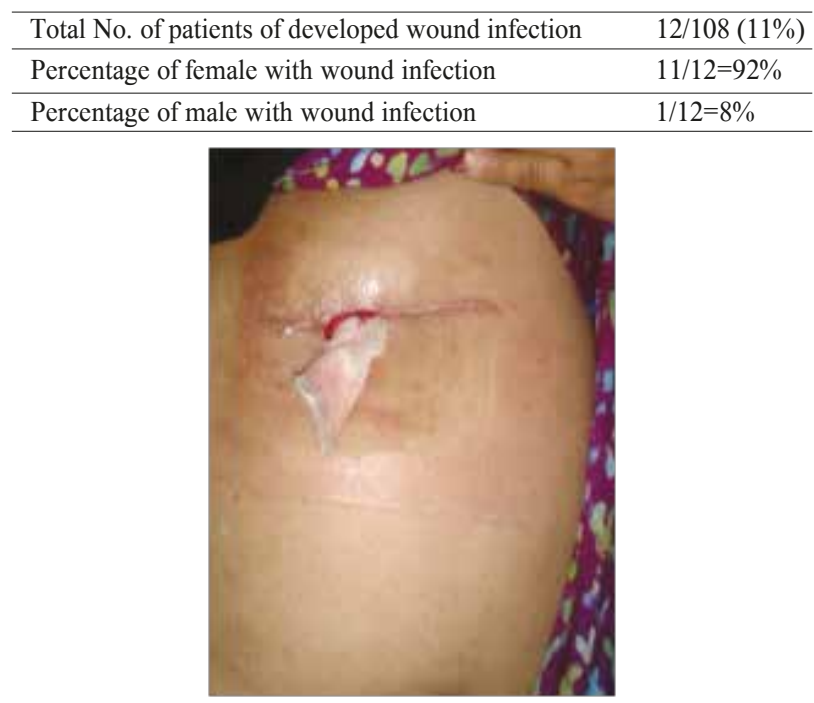

Figure-1: Superficial port site infection.

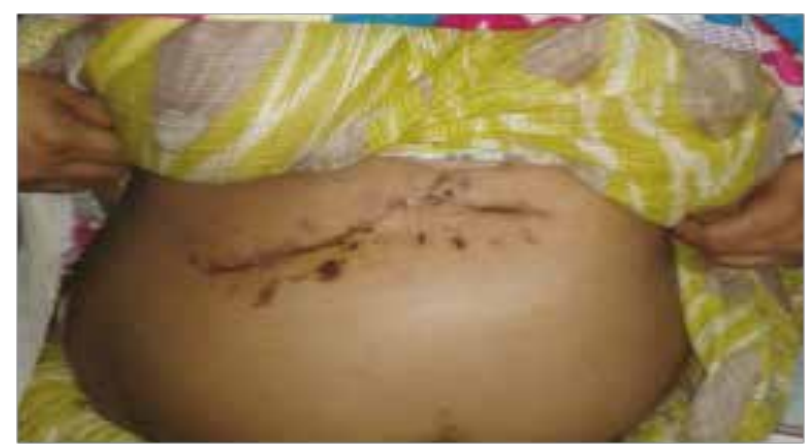

Figure-2: Large and deep Port site infection.

\section{Discussion:}

The LC was introduced in 1987 since then it is gaining popularity day by day. Open cholecystectomy procedure has been reduced to less than $20 \%$ in developed countries ${ }^{10}$. Now it is the treatment of choice and gold standard due to less pain, minimum surgical trauma, short postoperative hospital stay and early return to home ${ }^{11}$. No surgical procedure is without having complications.

Wound infection is the most common complication of almost every open surgery. Same applies to laparoscopic surgery. Although laparoscopic surgeries have less incidence of port site infections, still they can produce undesirable effects and increase morbidity ${ }^{12}$. LC is now performed commonly throughout the world and it has been accepted as safe out-patients procedure ${ }^{13}$.

In this study majority patients were females with a female to male ratio of $92: 16=5.6: 1$. Mean age was 37.57 years and this is consistent with most of the international and national literature ${ }^{14}$.

The frequency of PSI observed in our study was $11 \%$. Our results are comparable to Shindholimath et $\mathrm{al}^{15}$ who has reported an incidence of $6.3 \%$, while, Den Hoed et al 16 and Jan et $\mathrm{al}^{17}$ reported an incidence of 5.3\% and 5.07\% respectively. In contrary to our results, Zitser et al and Colizza et al reported a significantly decreased incidences i.e., $2.3 \%$ and $<2 \%$, respectively ${ }^{18,19}$.

Twelve patients $(11 \%)$ had wound infection at the port site through which the gall bladder was extracted. Nine patients were managed by simple dressing and antibiotics according to culture and sensitivity and three patient need incision and drainage. In the international literature port site wound infection was observed in less than $1 \%$ however in national studies, it was reported up to $8 \%{ }^{20,21}$.

The higher incidence of port site wound infection in our studies as compared to international studies was reported because of spillage of bile or gallstones at the wound site at the time of extraction of gallbladder, use of reusable ports after sterilization and diabetes mellitus. The cost of disposable ports for every case is not affordable by the patient nor by the hospital. However the use of collection bag for extraction of gall bladder can significantly reduce the incidence of wound infection.

In our study, most common port site affected by infection was epigastric port site (58\%), followed by umbilical port which got infected in 5 patients $(42 \%)$. Similar predominance of epigastric port site infection was noted by Jan et $\mathrm{al}^{17}$ and Hamzagaolu et al. ${ }^{22}$ But studies conducted by Colizza et $\mathrm{al}^{19}$ and Tocchi et $\mathrm{al}^{23}$ have shown that PSI is more common at the umbilical port site. Increased incidence of infection affecting epigastric over umbilical port site was due to repeated extraction of gall bladder through epigastric port site.

While evaluating the reasons for such port site lesions we could ascertain that in most of the cases the sterilization of the laparoscopic instruments was not proper.The laparoscopic instruments are insulated and have multiple joints and crevices which can harbour mycobacterial spores and other organisms which later germinate in the subcutaneous tissue and cause port site tuberculosis or 
infection ${ }^{24}$. Hence it is of paramount importance to clean the instruments of the charred tissue and or clotted blood as these act as nidus for the bacteria. A proper cleaning of the instrument is best achieved by ultrasonic technology ${ }^{24}$. Moreover the normal practice of using tap water for washing has to be discarded as it is the principal source of atypical mycobacteria. Most of the studies recommend washing with autoclaved water and or sterile normal saline and immediate drying of the instruments ${ }^{25}$.

The most commonly used agent for sterilization of laparoscopic instruments is $2 \%$ glutaraldehyde. Instruments (both ports with trocars and hand instruments) need to be immersed in the said solution for at least 10 hours for proper sterilization and a minimum of twenty minutes for disinfection. The solution has to be changed every two weeks or earlier depending upon the surgical burden of cases.

Ethylene oxide gas sterilization is a better option instead, however it is not available at all centers. Although a higher concentration of glutaraldehyde has been advocated but some studies have reported resistance to even higher concentration $^{24}$. Orthophthaldehyde and per acetic acid may be used as a viable option as reported by Prakash K Sasmal et $\mathrm{al}^{24}$. We recommend routine autoclaving of the ports along with trocars and or using a higher strength of glutaraldehyde for insulated hand instruments. Time taken for sterilization and disinfection is very important and should be strictly adhered to where ever the menace is prevalent.

\section{Conclusion:}

With innovation of minimal invasive surgery (MIS) the risk of wound infection has decreased considerably. All the advantages of the MIS are drained with the PSI. PSI, which not only disturbs the patient, but also agitates the operating surgeons, because it not just increase the duration of recovery but also increase the cost. We feel it can be reduced by adopting strict antiseptic measure, with no compromise on sterilization or by using disposable instruments.

\section{Conflict of Interest: None.}

Acknowledgement:

The research team would like to thank, health staff and patients for participating in the clinical trial. Special thanks to Professor Dr. KGM Iqbal and Professor Dr. MA Hashem Bhuiya for their advice and inspired for research article.

\section{References:}

1. Dugg P, Shivhare P, Singh H, Mittal S, Kumar A, Munghate A. A Prospective Analysis of Port Site Complications in Laparoscopic Cholecystectomy. J Minim Invasive Surg Sci. 2014; 3(2):e17634

https://doi.org/10.5455/aces.20140108064318
2. Soper NJ, Stockmann PT, Dunnegan DL, Ashley SW. Laparoscopic cholecystectomy. The new 'gold standard'? Arch Surg. 1992; 127(8):917-21.

https://doi.org/10.1001/archsurg.1992.01420080051008

PMid:1386505

3. Memon MR, Memon SR, Soomro AA, Shah SQA. Experience of laparoscopic cholecystectomy at Sukkur. Med Channel. 2010; 16: 290-4.

4. Garner JS, Jarvis WR, Emori TG, Horan TC, Hughes JM: CDC definitions for nosocomial infections. Am J Infect Control. 1988; 85: 818-827.

5. Mouret P. From the first laparoscopic cholecystectomy to the frontiers of laparoscopic surgery: the future prospectives. Dig Surg. 1991; 8:124-5.

https://doi.org/10.1159/000172015

6. Ramzanali SA, ZIA-ul-Islam, Shah SS. Monopolar Electrocautery versus Ultrasonic Dissection of the Gallbladder from the Gallbladder Bed in Laparoscopic Cholecystectomy. J Ayub Med Coll Abbotabad. 2013; 25(3-4): 16-8.

7. Khan N, Siddiq G. Outcome of caparoscopic cholecystectomy for Gallstones disease in patients with liver cirrhosis. J Ayub Med Coll Abbottabad. 2013; 25(1-2):36-9.

8. Panagiotopoulou IG, Carter N, Lewis MC, Rao S. Early laparoscopic cholecystectomy in a district general hospital: is it safe and feasible? Int J Evid Based Health. 2012; 10(2):112-6.

https://doi.org/10.1111/j.1744-1609.2012.00260.x

PMid:22672600

9. Mohammad S, Hinduja T, Fatima S. Complications of Laparoscopic Cholecystectomy in Acute Cholecystitis. J Surg Pak. 2008; 13(2):59-61.

10. Purkayastha S, Tilney HS, Georgiou P, Athanasiou T, Tekkis PP, Darzi AW. Laparoscopic cholecystectomy versus minilaparotomy cholecystectomy: a meta-analysis of randomized control trials. Surg Endosc. 2007; 21(8):1294-300.

https://doi.org/10.1007/s00464-007-9210-3

PMid:17516122

11. Pazouki A, Cheraghali R, Saeedimotahhar H, Jesmi F, Jangjoo A, Pishgahroudsari M. Pre-operative Rectal Indomethacin for Reduction of Postoperative Nausea and Vomiting after Laparoscopic Cholecystectomy: A DoubleBlind Randomized Clinical Trial. J Coll Physicians Surg Pak. 2015; 25(1):56-9.

12. Targarona EM, Balagué C, Knook MM, Trías M. Laparoscopic surgery and surgical infection. $\mathrm{Br} \mathbf{J}$ Surg. 2000; 87:536-44.

https://doi.org/10.1046/j.1365-2168.2000.01429.x

PMid:10792307 
13. Chok KS, Yuen WK, Lau H, Lee F, Fan ST. Outpatient laparoscopic cholecystectomy in Hong Kong Chinese -- an outcome analysis. Asian J Surg. 2004:27: 313

https://doi.org/10.1016/S1015-9584(09)60058-0

14. Mufti TS, Ahmad S, Naveed D, Akbar M, Zafar A. Laparoscopic Cholecystectomy: An Early Experience at Ayub Teaching Hospital Abbottabad. J Ayub Med Coll Abbottabad. 2007; 19(4):42-4.

15. Shindholimath VV, Seenu V, Parshad R, Chaudhry R, Kumar A: Factors influencing wound infection following laparoscopic cholecystectomy. Trop Gastroenterol. 2003; 24: 90-92.

16. Den Hoed PT, Boelhouwer RU, Veen HF, Hop WC, Bruining HA. Infections and bacteriological data after laparoscopic and open gallbladder surgery. J Hosp Infect. 1998; 39: 27-37.

https://doi.org/10.1016/S0195-6701(98)90240-7

17. Jan WA, Ali IS, Shah NA, Ghani A, Khan M, Khan AS. The frequency of port-site infection in laparoscopic cholecystectomies. JPMI. 2008; 22(1): 66-70.

18. Zitser YG, Simchen E, Ferderber N, Freund HR. A trend for reduced 15-day wound infection and 6 months' mortality in laparoscopic relative to open cholecystectomy: the Israeli Study of Surgical Infections. Clin Perform Qual Health Care. 1997; 5: 116-122.

19. Colizza S, Rossi S, Picardi B, Carnuccio P, Pollicita S, Rodio F, et al. Surgical infections after laparoscopic cholecystectomy: Ceftriaxone vs ceftazidime antibiotic prophylaxis. A prospective study. Chir Ital. 2004; 56: 397-402.

20. Vecchio R, MacFadyen BV, Latteri S. Laparoscopic cholecystectomy: an Analysis on 114,005 cases of United States series. Int Surg. 1998; 83(3):215-9.
21. Dholia KM, Memon AA, Shaikh MS. Laparoscopic Cholecystectomy: Experience of 100 cases at a teaching hospital of Sindh. J Liaquat Univ Med Health Sci. 2005; 105-8.

https://doi.org/10.22442/jlumhs.05430070

22. Hamzaoglu I, Baca B, Böler DE, Polat E, Ozer Y. Is umbilical flora responsible for wound infection after laparoscopic surgery? Surg Laparosc Endosc Percutan Tech. 2004; 14: 263-267.

https://doi.org/10.1097/00129689-200410000-00007

\section{PMid:15492655}

23. Tocchi A, Lepre L, Costa G, Liotta G, Mazzoni G, Maggiolini F. The need for antibiotic prophylaxis in elective laparoscopic cholecystectomy: a prospective randomized study. Arch Surg. 2000; 135: 67-70.

https://doi.org/10.1001/archsurg.135.1.67

PMid: 10636350

24. Prakash K Sasmal, Tushar S Mishra, SatyajitRath. Port site infection in laparoscopic surgery: A review of its management. World J Clin Cases. 2015 Oct 16; 3(10): 864- 871

https://doi.org/10.12998/wjcc.v3.i10.864

PMid:26488021 PMCid:PMC4607803

25. Lorena NS, Pitombo MB, Côrtes PB. Mycobacterium massiliense BRA100 strain recovered from postsurgicalinfections: resistance to high concentrations of glutaraldehyde and alternative solutions for high level disinfection. Acta Cir Bras. 2010; 25:455-459.

https://doi.org/10.1590/S0102-86502010000500013

PMid:20877958 